\title{
Kebijakan Kriminal dalam Menanggulangi Kejahatan Kesusilaan
}

\section{Melalui Internet}

\author{
Mus Muliadin1, Fajar Dian Aryani, Evy Indriasari, Erwin Aditya Pratama \\ STIH Bima Nusa Tenggara Barat, Universitas Pancasakti Tegal \\ Masuk: 24 November 2020; Diterima: 30 November 2020; Terbit: 30 November 2020. \\ DOI: $10.24905 /$ diktum.v8i2.102
}

\begin{abstract}
The development of cybercrime as a new form of crime in the cybersex world has been galvanized globally as a dark shadow of technological advances in the field of communication and information. because it allows for new forms of exploitation, new opportunities for criminal activity, and even new forms of crime. One of the cybercrime problems that is also very troubling and gets the attention of various circles, is the cybercrime problem in the field of decency. The research approach uses a normative juridical approach, the data consists of secondary data obtained through literature studies, and the data is analyzed analytically. Cybersex is a new form of adultery so clear legal arrangements are needed to be able to anticipate it. In addition to these penal efforts, non-penal (integral/systemic) should be put forward to overcome cybersex. Cybersex can be done by law enforcement with the positive laws that exist at this time by carrying out legal construction. Besides, the regulation by Positive Law of Indonesia is still spread in various laws and regulations and there are still some shortcomings so that in the future anticipatory policies of criminal law must be dating.
\end{abstract}

Keywords: Crime, Decency, Internet, Cybersex

\begin{abstract}
Abstrak
Perkembangan cybercrime sebagai bentuk baru kejahatan di dunia cyberspace telah menggenjala secara global sebagai bayangan gelap (a dark shadow) kemajuan teknologi di bidang komunikasi dan informasi. karena memungkinkan terjadinya bentuk-bentuk eksploitasi baru, kesempatan baru untuk aktivitas kejahatan, dan bahkan bentuk-bentuk baru dari kejahatan. Salah satu masalah cybercrime yang juga sangat meresahkan dan mendapat perhatian berbagai kalangan, adalah masalah cybercrime di bidang kesusilaan. Pendekatan penelitian menggunakan pendekatan yuridis normatif, data terdiri dari data sekunder yang didapatkan melalui studi kepustakaan, dan data dianalisis secara diskriptif analitis. Cybersex adalah merupakan bentuk baru perzinahan sehingga diperlukan pengaturan hukum yang jelas untuk dapat mengantisipasinya. Selain upaya penal tersebut upaya non penal (integral/sistemik) harus dikedepankan untuk menanggulangi cybersex. Terhadap cybersex dapat dilakukan penegakan hukum dengan hukum positif yang ada pada saat ini dengan melakukan konstruksi hukum. Selain itu juga pengaturan oleh hukum positif Indonesia masih tersebar dalam berbagai peraturan perundangundangan dan masih terdapat beberapa kekurangan, sehingga kedepannya diperlukan kebijakan antisipatif hukum pidana yang akan dating.
\end{abstract}

Kata Kunci: Kriminal, Kesusilaan, Internet, Cybersex

\footnotetext{
${ }^{1}$ Coresponding author:

Musmuliadinbima1992@gmail.com
} 


\section{A. Pendahuluan}

Penerapan teknologi internet telah menyentuh seluruh aspek kehidupan masyarakat. Hal ini telah menyebabkan perubahan cara berpikir dan bertindak masyarakat suatu bangsa. Tak terkecuali perubahan sikap masyarakat terhadap hukum yang berlaku. (Wahid, 2005) Penggunaan internet pun telah membentuk masyarakat dunia baru yang tidak dihalangi lagi oleh batas-batas-batas teritorial suatu negara yang dahulu ditetapkan sangat esensial sekali yaitu dunia maya, dunia yang tanpa batas (borderless world) dengan realitas virtual (virtual reality). (Raharjo, 2002) Di satu sisi, kemajuan teknologi canggih itu membawa dampak positif di berbagai kehidupan, seperti adanya e-mail, e-commerce, e-learning, EFTS (Electronic Funds Transfer System atau sistem transfer dana elektronik), Internet Banking, Cyber Bank, On-line Business dan sebagainya. Namun di sisi lain juga membawa dampak negatif, yaitu dengan munculnya berbagai jenis hitech crime dan cybercrime, sehingga dinyatakan bahwa cybercrime is the most recent type of crime (Dudeja, 2002) dan cybercrime is part of the seamy side of the Information Society (Cybercrime merupakan bagian sisi paling buruk dari Masyarakat Informasi). (Party, 2001)

Perkembangan cybercrime sebagai bentuk baru kejahatan di dunia cyber space (Wahid, 2005) telah menggenjala secara global sebagai bayangan gelap ( $a$ dark shadow) kemajuan teknologi di bidang komunikasi dan informasi. karena memungkinkan terjadinya bentuk-bentuk eksploitasi baru, kesempatan baru untuk aktivitas kejahatan, dan bahkan bentuk-bentuk baru dari kejahatan. Salah satu masalah cybercrime yang juga sangat meresahkan dan mendapat perhatian berbagai kalangan, adalah masalah cybercrime di bidang kesusilaan yang saat ini diseminarkan. Jenis cybercrime di bidang kesusilaan yang sering diungkapkan adalah cyber pornography (khususnya child pornography) dan cybersex (Arif, 2001). Di Internet atau dunia maya (virtual world) sangat mudah ditemukan bahanbahan pornografi atau yang berkaitan dengan masalah seksual, seperti yang 
dikemukakan oleh Mark Griffiths bahwa sex merupakan topik yang paling populer di internet (the most popular topic on the internet) (Griffiths, 2001). Menurut perkiraan, $40 \%$ dari berbagai situs di WWW menyediakan bahanbahan seperti itu (Brame, 1996). Senada dengan hal tersebut, Nathan Tabor mengatakan statistik menunjukan bahwa $25 \%$ dari semua internet, mesin pencarinya minta dihubungkan dengan pornografi (Tabor, 1996) dan diperkirakan $20 \%$ dari pemakai internet mengunjungi situs cyber sex dan terlibat dalam kegiatan ini (Maheu, n.d.). Penyalahgunaan internet di dunia maya kini belum ada peraturan perundangan-undangan yang mengaturnya secara khusus, terlebih yang dikaitkan dengan perbuatan asusila atau seks. Padahal di dunia cyber masalah yang berhubungan dengan seks menimbulkan berbagai permasalahan dalam aspek hukum, moral dan agama.

Cyber sex terkait dengan seks, jasa, dan aktivitas yang menyertakan internet di dalamnya. Cyber dalam konteks ini adalah suatu kata kerja, yang mengacu pada tindakan menikmati cyber sex, dalam defenisi yang paling tegas dan pendek cyber sex adalah, suatu kombinasi antara komunikasi dan masturbasi ( $a$ combination of communication and masturbation). Ini merupakan suatu kepuasan seksual bagi seseorang yang menginginkan hubungan dengan seseorang dan berkhayal dengan orang lain. Hampir serupa dengan telepon seks, perbedaan yang menonjol hanyalah sebutan metoda komunikasi. Banyak akibat negatif yang ditimbulkan dari cyber sex, bahkan ada yang sudah mengklasifikasikannya sebagai bentuk baru perzinahan. Melihat fakta tersebut maka perlu dilakukan pengkajian serius dan konseptual terhadap kebijakan penanggulangannya. Tidak adanya pengaturan yang tegas dan jelas dalam bidang hukum mengenai cyber sex menyebabkan makin maraknya perbuatan tersebut, sehingga dirasa perlu dicari bentuk aturan hukumnya yang tepat. Perkembangan teknologi informasi mengakibatkan modus operandi delik kesusilaan mengalami perkembangan, semula hanya sebatas perbuatan kesusilaan atau sex secara fisik, 
namun kini telah berkembang ke arah non fisik seperti cyber sex. Berhubung dengan pendahuluan di atas makalah ini hanya terbatas pada ruang lingkup yang berkaitan dengan cyber sex dengan perumusan masalah sebagai berikut: Apakah cyber sex dapat dikategorikan sebagai salah satu bentuk perzinahan yang merupakan bagian dari tindak pidana kesusilaan menurut hukum pidana. Serta apakah kebijakan hukum pidana indonesia yang ada saat ini dapat digunakan untuk menjangkau cyber sex.

\section{B. Metode penelitian}

Jenis penelitian yang digunakan dalam penelitian ini adalah penelitian hukum normatif, yaitu suatu jenis penelitian hukum yang diperoleh dari studi kepustakaan, dengan menganalisis suatu permasalahan hukum melalui peraturan perundang-undangan, literatur-literatur dan bahan-bahan referensi lainnya. Pada penelitian ini akan dikaji mengenai kejahatan cybersex dalam norma hukum positif di Indonesia.

Penulis menggunakan pendekatan kasus (case approach) dalam penulisan penelitian ini, karena penulisan yang didasari pada kasus yang terjadi di Indonesia yang telah mempunyai kekuatan hukum tetap banyak kasus hokum di Indonesia berkaitan dengan cybersex seperti yang dilakukan oleh para pejabat dan publik figur. Sumber data penelitian yang digunakan dalam penelitian ini meliputi Bahan hukum primer Undang-Undang nomor 28 tahun 2014 tentang Hak Cipta. Bahan hukum sekunder Bahan hukum yang memberikan penjelasan atas bahan hukum primer, yang terdiri dari literatur-literatur, dokumendokumen resmi seperti karangan para ahli ataupun sarjana. Bahan hukum tersier Bahan hukum yang memberikan petunjuk ataupun penjelasan terhadap bahan hukum primer dan sekunder seperti jurnal-jurnal hukum, kamus hukum, ensiklopedi, website dan lain sebagainya.

Metode pengumpulan dan pengelolaan data Teknik pengumpulan data merupakan cara mengumpulkan data-data yang dibutuhkan untuk menjawab 
rumusan masalah dalam suatu penelitian. Adapun teknik yang digunakan yaitu Teknik pengumpulan data yang digunakan dalam penelitian normatif ini adalah dengan studi pustaka atau bibliography study dimana sumber data yang digunakan merupakan sumber data sekunder yaitu melalui pendapat para ahli, tulisan-tulisan dalam buku ilmiah.

Metode analisis data, data yang telah dikumpulkan dianalisa secara deskriptif analisis, yaitu mengemukakan seluruh permasalahan yang ada dengan tepat dan sejelas-jelasnya. Kemudian penguraian tersebut ditarik kesimpulan secara induktif, dimana suatu kesimpulan ditarik dari pernyataan yang bersifat khusus ke umum, sehingga penyajian hasil pembahasan dapat dipahami dengan mudah.

\section{Pembahasan}

\section{Cyber Crime di Bidang Kesusilaan}

Secara singkat dapat dikatakan, bahwa delik kesusilaan adalah delik yang berhubungan dengan (masalah) kesusilaan. Namun tidaklah mudah menetapkan batas-batas atau ruang lingkup delik kesusilaan, karena pengertian dan batas-batas kesusilaan itu cukup luas dan dapat berbedabeda menurut pandangan dan nilai-nilai yang berlaku di dalam masyarakat (Arif, 2001), sehingga pada dasarnya setiap delik atau tindak pidana merupakan delik kesusilaan. Secara yuridis, delik kesusilaan menurut KUHP yang berlaku saat ini terdiri dari 2 (dua) kelompok tindak pidana, yaitu kejahatan kesusilaan diatur dalam Bab XIV Buku II dan pelanggaran kesusilaan (diatur dalam Bab VI Buku III). Kelompok kejahatan kesusilaan Pasal 281-303 KUHP sedangkan pelanggaran kesusilaan menurut KUHP Pasal 532-54. sementara jika diamati berdasrkan kenyataan sehari-hari, persepsi masyarakat tentang arti kesusilaan lebih condong kepada kelakuan yang benar atau salah khususnya dalam hubungan seksual (behaviour as to right or wrong especially 
in relation to sexual matter) (Arif, 2001). Telah dikemukakan di atas, bahwa orang bisa berbeda pendapat mengenai batasan pengertian dan ruang lingkup delik kesusilaan. Prof. Mr. Roeslan Saleh misalnya pernah mengemukakan, bahwa pengertian kesusilaan hendaknya tidak dibatasi pada pengertian kesusilaan dalam bidang seksual, tetapi juga meliputi halhal lain yang termasuk dalam norma-norma kepatutan bertingkah laku dalam pergaulan masyarakat. Oleh karena itu beliau menyarankan, agar tindak pidana berupa meninggalkan orang yang perlu ditolong, penghinaan, dan membuka rahasia juga dimasukkan ke dalam tindak pidana terhadap kesusilaan (Saleh, 1985).

Berbagai KUHP Asing, pengelompokan delik kesusilaan juga berbeda-beda dan tampaknya bergantung pada kesepakatan dan kebijakan pembuat undang-undang. (Arief, 2002) Walaupun pengelompokan atau ruang lingkup delik kesusilaan bisa berbeda-beda, namun patut dicatat pendapat Prof. Mr. Roeslan Saleh yang menggaris bawahi pandangan Prof. Oemar Senoadji, bahwa dalam menentukan isi (materi/substansi)-nya harus bersumber dan mendapat sandaran kuat dari moral agama. Pandangan yang demikian walaupun patut ditambahkan, bahwa penentuan delik kesusilaan juga harus berorientasi pada nilai-nilai kesusilaan nasional (NKN) yang telah disepakati bersama dan juga memperhatikan nilai-nilai kesusilaan yang hidup di dalam masyarakat. Nilai Kesusilaan Nasional ini dapat digali antara lain dari produk legislatif nasional (berbentuk Undang-undang Dasar atau undang-undang). Dalam struktur masyarakat Indonesia, Nilai Kesusilaan Nasional itu pun tentunya bersumber dari nilai-nilai agama dan kesusilaan yang hidup di tengahtengah masyarakat (Arif, 2001). Sesuai dengan pendapat di atas tentang batasan dan ruang lingkup tindak pidana kesusilaan sebagaimana terurai diatas, Mulyana W Kusuma juga menyatakan bahwa Kejahatan seks serta 
Kejahatan yang menyangkut seks (sex related crimes) yang dirumuskan dalam hukum pidana sebagai delik susila senantiasa harus dipahami secar kontekstual dalam hubungannya dengan perkembangan budaya dan perubahan-perubahan struktur sosial yang ada di masyarakat (Kusuma, 1993). Perkembangan teknologi informasi, dalam hal internet telah mengakibatkan perubahan ditengah masyarakat. System tata nilai di dalam suatu masyarakat berubah dari yang bersifat local particular menjadi globaluniversal. Hal ini pada akhirnya akan membawa dampak pada pergeseran nilai dan norma khususnya norma hukum dan kesusilaan.

Kemajuan teknologi ternyata tidak digunakan sebagai sarana positif untuk meningkatkan kualitas kehidupan, tetapi justeru digunakan sebagai sarana negative yang dapat membawa dampak negative. Keprihatian terhadap dampak negatif dari teknologi maju tersebut pernah dikemukakan oleh Art Bowker, seorang ahli Computer crime dari Amerika yang menyatakan bahwa teknologi maju telah meningkat menjadi way of life masyarakat kita, tetapi sangat disayangkan teknologi maju ini menjadi alat atau sarana pilihan bagi para pelaku cybersex (cybersex offender). Berbagai delik kesusilaan yang dikemukakan di atas, dapat juga terjadi di ruang maya (cyber space), terutama yang berkaitan dengan masalah pornografi, mucikari/calo, dan pelanggaran kesusilaan/ percabulan/ perbuatan tidak senonoh/ zina. Semakin maraknya pelanggaran kesusilaan di dunia cyber ini, terlihat dengan munculnya berbagai istilah seperti: cyber porno-graphy (khususnya child pornography), on-line pornography, cyber sex, cyber sexer, cyber lover, cyber romance, cyber affair, on-line romance, sex on-line, cybersex addicts, cyber sex offender.

\section{Cyber Sex dan Akibat-Akibatnya}

Menurut Peter David Goldberg, cybe sex adalah penggunaan internet untuk tujuan-tujuan seksual (the use of the Internet for sexual purposes) 
(Goldberg, 2004). Senada dengan ini, Dr. David Greenfield mengemukakan, bahwa cybersex adalah menggunakan komputer untuk setiap bentuk ekspresi atau kepuasan seksual (using the computer for any form of sexual expression or gratification. Dikemukakan juga olehnya, bahwa cybersex dapat dipandang sebagai kepuasan/kegembiraan maya (virtual gratification), dan suatu bentuk baru dari keintiman (a new type of intimacy)

(Brame G. G.). Patut dicatat, bahwa hubungan intim atau keintiman

(intimacy) itu dapat juga mengandung arti hubungan seksual atau perzinahan (Shadily, 2000). Ini berarti, cybersex merupakan bentuk baru dari perzinahan. Dalam ensiklopedia bebas Wikipedia dinyatakan, bahwa Cybersex atau computer sex adalah pertemuan sex secara virtual/maya antara dua orang atau lebih yang terhubung melalui jaringan internet dengan mengirimkan pesan-pesan seksual yang menggambarkan suatu pengalaman seksual. Cybersex/computer sex merupakan bentuk permainan peran (role-playing) antara para partisipan yang berpura-pura atau menganggap dirinya melakukan hubungan seksual secara nyata, dengan menggambarkan sesuatu untuk mendorong perasaan/fantasi seksual mereka. Cybersex ini terkadang disebut juga dengan istilah cybering. Menurut Greenfield dan Orzack, cybering ini dimasukkan dalam penggolongan cyber sex yang berupa Online Sexual Activity (OSA) karena dengan cybering itu, salah seorang atau kedua orang yang saling berfantasi itu dapat melakukan masturbasi (onani) (Goldberg, 2004). Bahkan menurut

Kenneth Allen, An important and major element of cybersexual activity is masturbation (Allen). Pengertian Cybering atau sex on the Internet dikemukakan pula oleh Michael G. Conner, Psy.D sebagai “diskusi seksual secara online dengan tujuan mencapai orgasme (puncak syahwat. (Conner)

Akibat/Dampak Negatif Cybersex, meningkatnya cybersex mengundang minat orang untuk melakukan berbagai penelitian. 
Penelitian yang telah dilakukan di Amerika, antara lain: (1) Cooper dan kawan-kawan, 2000, meneliti tentang ciri-ciri dan pola kebiasaan para pecandu cybersex (cybersex addicts); (2) Schneider, 2000, meneliti tentang pengaruh/akibat penggunaan cybersex terhadap pasangan mereka sendiri (suami/istri); dan (3) Peter David Goldberg, 2004, meneliti tentang “pengalaman para terapis keluarga dan perkawinan terhadap klien yang mengalami konflik akibat penggunaan cybersex. Berdasarkan penelitian tersebut, banyak dijumpai akibat-akibat negatif dari penggunaan cybersex terhadap diri sipelaku maupun terhadap hubungan perkawinan, terhadap keseluruhan hubungan/sistem kekeluargaan, dan terhadap anak-anak mereka. Akibat terhadap diri pelaku, antara lain, merubah pola tidur, mengisolasi diri dari keluarga, mengabaikan tanggung jawab, berdusta, berubahnya kepribadian, kehilangan daya tarik terhadap partnernya (istri/suaminya), bersifat ambigius/mendua, timbul perasaan malu dan bersalah, hilangnya rangsangan nafsu dan adanya gangguan ereksi (erectile dysfunction). Akibat terhadap partnernya (istri/suami) dan anak-anak, antara lain timbul perasaan dikhianati, dilukai, dikesampingkan, dihancurkan, ditelantarkan, kesepian, malu, cemburu, kehilangan harga diri, perasaan dihina, anak-anak merasa kehilangan perhatian orang tua, depresi (karena pertengkaran orang tua). (Goldberg, 2004) Adanya akibatakibat demikian, maka sering timbul pertengkaran keluarga yang berakibat pada perceraian. Menurut Carl Salisbury (pengacara di Hanover, New York), gugatan perkara yang berkaitan dengan cybersex menunjukkan peningkatan di pengadilan-pengadilan Amerika. Dikatakan pula olehnya. Tidak dapat dihindari bahwa kita sedang menyaksikan semakin banyaknya kasus-kasus perceraian yang disebabkan oleh cybersex (Goldberg, 2004). Cukup banyaknya akibat negatif dari cybercrime di 
bidang kesusilaan dan berbagai bidang lainnya, tentunya memerlukan kajian serius terhadap kebijakan penanggulangannya.

\section{Kebijakan Kriminal Dalam Penanggulangan Kejahatan Kesusilaan Yang}

\section{Bersaranakan Internet (Cyber Sex)}

Dilihat dari sudut criminal policy, upaya penanggulangan kejahatan (termasuk penanggulangan cybersex) tentunya tidak dapat dilakukan secara parsial dengan hukum pidana (sarana penal), tetapi harus ditempuh pula dengan pendekatan integral/sistemik. Sebagai salah satu bentuk dari hitech crime, adalah wajar upaya penanggulangan cybersex juga harus ditempuh dengan pendekatan teknologi (techno prevention). Di samping itu diperlukan pula pendekatan budaya/kultural, pendekatan moral/edukatif (terlebih untuk delik kesusilaan), dan bahkan pendekatan global (kerja sama internasional) karena cybersex dapat melampaui batas-batas negara (bersifat transnational/ transborder).

Kebijakan Penanggulangan (Penegakan Hukum) Dengan Hukum Pidana Positif Terhadap Cybersex. Berdasarkan pengertian cybersex yang telah dikemukakan di atas, dapat diidentifikasikan adanya pendapat, bahwa cybersex/computer sex:

a. Penggunaan internet untuk tujuan-tujuan seksual;

b. Penggunaan komputer untuk setiap bentuk ekspresi atau kepuasan seksual;

c. Merupakan bentuk baru dari keintiman (a new type of intimacy), yang dapat juga diartikan sebagai "bentuk baru dari perzinahan atau hubungan seksual yang gelap/haram/melanggar hukum" ("illicit sexual relations);

d. Dapat dipandang sebagai bentuk ekspresi atau kepuasan seksual maya (virtual sex expression/gratification) 
e. Merupakan bentuk pertemuan sex secara virtual/maya (virtual sex encounter) atau sex online;

f. Pertemuan dua orang atau lebih yang terhubung melalui jaringan internet dengan mengirimkan pesan-pesan seksual atau menggambarkan pengalaman seksual untuk membangkitkan rangsangan/perasaan/fantasi seksual, sehingga terjadi masturbasi (onani);

g. Dilihat dari sudut akibat, banyak dampak negatif bagi sipelaku sendiri, me-retakkan/merusak/menghancurkan harmonisasi hubungan perkawinan, merusak sistem kekeluargaan, dan merusak/membahayakan anak-anak.

Mengamati hal-hal di atas, nampaknya cybersex sulit dijangkau oleh hukum pidana positif saat ini, karena perbuatannya bersifat maya/abstrak/ non-fisik dan sangat individual. Walaupun dinyatakan di atas, bahwa cybersex merupakan bentuk lain dari perzinahan atau hubungan seksual gelap/ haram/melanggar hukum (illicit sexual relations), namun sulit dijaring dengan Pasal 284 KUHP kalau pengertian zinah selalu dikaitkan pada adanya hubungan seksual (persetubuhan) secara fisik. Inilah salah satu kelemahan hukum pidana konvensional saat ini yang selalu bertolak dari paradigma perbuatan dalam arti fisik/materiel. Namun sekiranya dalam praktek peradilan, khususnya dalam kasus cybersex ini, hakim akan melakukan konstruksi hukum dengan menyatakan bahwa cybersex atau hubungan seksual non-fisik (maya) ini merupakan bentuk zina dalam pengertian Pasal $284 \mathrm{KUHP}$, maka menurut saya konstruksi hukum demikian cukup beralasan, mengingat:

a) Pasal 284 sendiri tidak memberikan pengertian/batasan yuridis tentang apa yang dimaksud dengan zinah; dengan kata lain, Pasal 284 sama sekali tidak menyebutkan unsur-unsur zinah secara eksplisit; 
b) Adanya unsur hubungan seksual/persetubuhan secara fisik hanya merupakan pendapat umum dan pendapat yang berkembang dalam teori/doktrin maupun yurisprudensi;

c) Pendapat umum/doktrin/yurisprudensi itu didasarkan pada paradigma/ konsep perbuatan dalam arti materiel/fisik, sedangkan saat ini ada perkembangan paradigma/ konsep perbuatan secara fungsional dan secara keilmuan;

d) Penafsiran yang bertolak dari paradigma fungsional dan paradigma keilmuan terhadap beberapa pengertian hukum (seperti perbuatan, barang, subjek hukum, orang) sudah dikembangkan/digunakan dalam praktek pembuatan UU dan yurisprudensi selama ini;

e) Beberapa kasus pencurian dalam yurisprudensi telah juga diartikan secara non-fisik, misalnya kasus pencurian listrik (Arrest HR 23 Mei 1921) dan kasus pembobolan dana BNI 1946 New York Agency melalui komputer (dengan transfer electronic payment system) yang dinyatakan oleh Mahkamah Agung RI dalam Putusan MA-RI No. 1852 K./Pid/1988 tgl. 21 Desember 1988 sebagai pencurian (berarti mengambil barang secara non-fisik);

f) Dalam sumber artikel di internet yang berjudul Cyber Sex There are organizations out there to help you dinyatakan, bahwa cybersex merupakan adultery (zinah). Dikemukakan dalam tulisan itu, intinya sebagai berikut:

Untuk orang yang sudah menikah, melakukan aktivitas cybersex merupakan suatu bentuk perzinahan (For a married person to engage in this activity constitutes a form of adultery). Dilihat dari sudut hukum, hal itu merupakan wilayah kelabu, namun hal itu hanya disebabkan pengadilan tidak dapat 
mengejar waktu. Pengadilan dapat menetapkan cybersex itu sebagai perzinahan (adultery) atau sebagai bentuk penelantaran (abandonment). Dilihat secara moral, jelas me-rupakan bentuk penipuan (form of cheating), dan dari sudut agama merupakan bentuk perzinahan (form of adultery)".

Dilihat dari sudut pandang agama Islam, jelas cybersex itu merupakan zinah. Hal ini dikemukakan oleh Dr. Muzammil H. Siddiqi (mantan President of the Islamic Society of North America) sewaktu menjawab pertanyaan seseorang melalui internet, "apakah cybersex dan phone sex merupakan zina" (Is cybersex or phone sex considered an adultery (Zina)?). Ia menjawab : (Pakistan Fatwa)

"Zina menurut syari'ah adalah setiap hubungan seksual yang haram/ terlarang. Oleh karena itu, seks sebelum nikah, di luar nikah, dan homoseks, semuanya adalah zina. Zina merupakan dosa besar dan mutlak dilarang (haram). Islam tidak hanya melarang hubungan sek-sual yang haram, tetapi juga melarang setiap perbuatan yang mengarah/mendekati dosa ini. Cybersex, phone sex dan sebagainya merupakan perbuatan yang dapat mengarah/mendekati zina".

(Zina according to Shari ah is any illicit sexual intercourse. Thus pre-marital sex, extra marital sex and homosexuality are all considered Zina according to Islamic law. Zina is a major sin (Kabirah); It is absolutely forbidden. Islam does not only forbid illicit sexual intercourse, but also forbids anything that leads to this sin and crime. 'Cybersex', 'phone sex', etc. are those activities that can lead to Zina"). 
Dengan uraian di atas, dapatlah disimpulkan bahwa konstruksi "cybersex" sebagai bentuk zina, cukup beralasan dilihat dari sudut : (a) yuridis normatif, (b) yuridis konseptual/teoritik/keilmuan, yurisprudensi, (d) Pandangan pakar/artikel cybercrime (cybersex), (e) Agama, dan dari sudut (f) Akibat sosial (dampak negatif)-nya.

\section{Simpulan}

Dari uraian pembahasan diatas maka dapat disimpulkan bahwa Cybersex adalah merupakan bentuk baru perzinahan sehingga diperlukan pengaturan hukum yang jelas untuk dapat mengantisipasinya. Selain upaya penal tersebut upaya non penal (integral/sistemik) harus dikedepankan untuk menanggulangi cybersex. Terhadap cybersex dapat dilakukan penegakan hukum dengan hukum positif yang ada pada saat ini dengan melakukan konstruksi hukum. Selain itu juga pengaturan oleh hukum positif Indonesia masih tersebar dalam berbagai peraturan perundang-undangan dan masih terdapat beberapa kekurangan, sehingga kedepannya diperlukan kebijakan antisipatif hukum pidana yang akan datang.

\section{Daftar Pustaka}

Allen, K. (n.d.). Cyber-Sex A Review and Implications of the Situation. Retrieved from earthlink: home.earthlink.net

Arief, B. N. (2002). Bunga Rampai Kebijakan Hukum Pidana. In Perbandingan Hukum Pidana .

Arif, B. N. (2001). Antisipasi Hukum Pidana Antisipasi Penanggulangan Cyber-Crime Dengan Hukum Pidana. Bandung: STHB Bandung.

Brame, G. G. (n.d.). Retrieved from Gloria Brame: gloriabrame.com/glory/journ7.html

Brame, G. G. (1996). How to Have Cyber Sex Boot Up And Turn On. Retrieved from http:/www.gloria-brame.com/glory/journ.htm. 
Conner, M. G. (n.d.). Internet Addiction $\mathcal{E}$ Cyber Sex. Retrieved from CrisisCounseling: www.CrisisCounseling.org

Dudeja, V. (2002). Cyber Crimes and Law. Seminar Kejahatan Seks melalui Cyber Crime dalam Perspektif Agama, Hukum, dan Perlindungan Korban. 2, p. 1. Cirebon: FH UNSWAGATI.

Goldberg, P. D. (2004). Retrieved from pedrogoldberg: pedrogoldberg@aol.com Griffiths, M. (2001, November). Sex on the Internet: observations and Implications for Internet sex Addiction. Journal of Sex Research, 23. Retrieved from mark.griffiths@ntu.ac.uk

Kusuma, M. W. (1993). Perumusan Tindak Pidana Kesusilaan (Perzinahan dan Pemerkosaan) dalam Rancangan KUHP Baru ditinjau dari Aspek Kebijkana Kriminal dan Aspek Sosial dan Budaya. Makalah disajikan dalam seminar sehari tentang Tinjauan Terhadap Rancangan KUHP Baru khususnya Tindak Pidana Kesusilaan (p. 1). Semarang: Universitas Katolik Soegijapranat.

Maheu, M. M. (n.d.). Retrieved from http:/www.selfhelpmagazine.com

Pakistan Fatwa. (n.d.). Retrieved from Islamonline.net: http://pakistanlink.com/religion/2001/0413. html

Party, D. P. (2001). “Opinion 4/2001 On the Council of Europe's Draft Convention on Cybercrime", adopted on 22 March 2001. Europe: Council of Europe.

Raharjo, A. (2002). Cyber Crime, Pemahaman dan Upaya Pencegahan Kejahatan Berteknologi. Bandung: PT. Citra Aditya Bakti.

Saleh, R. (1985). Bab-bab Kodifikasi Hukum Pidana (Buku II). Jakarta: BPHN Departemen Kehakiman.

Shadily, J. M. (2000). Kamus Inggris Indonesia.

Tabor, N. (1996). theconervativevoice. Retrieved from theconervativevoice: http:/www.theconervativevoice.com

Wahid, A. (2005). Kejahatan Mayantara 2005. Bandung: Refika Aditama. 